\title{
FORMULAÇÃO E IMPLEMENTAÇÃO DAS POLÍTICAS PÚBLICAS EM EDUCAÇÃO E AS PARCERIAS PÚBLICO-PRIVADAS: IMPASSE DEMOCRÁTICO OU MISTIFICAÇÃO POLÍTICA?
}

LISETE R.G. ARELARO

RESUMO: Dois impasses estão presentes na gestão dos sistemas escolares no Brasil: o discurso sobre a gestão democrática na formulação e implementação das políticas públicas em educação e a prática "produtivista" que prescinde da mesma. Concomitante aos movimentos de pressão social para o estabelecimento da "transparência" das ações governamentais, exigindo participação ampliada da população - por meio de conselhos ou equivalentes -, a pressão pela "qualidade" do ensino e de gestão educacional "competente" vem exigindo dos dirigentes públicos respostas imediatas. $\mathrm{Na}$ ausência de condiçôes para efetivá-las, estabelecem "parcerias" público-privado que implementam a lógica do mercado nas orientaçōes dadas às escolas e nos sistemas públicos de ensino, gestando um novo e contraditório conceito de eficiência educacional, em que a participação dos diferentes segmentos da comunidade escolar é dispensada.

Palavras-chave: Política educacional. Educação básica. Parceria público-privado.

FORMULATION AND IMPLEMENTATION OF PUBLIC POLICIES IN EDUCATION AND THE PUBLIC-PRIVATE PARTNERSHIPS: A DEMOCRATIC IMPASSE OR A POLITICAL MYSTIFICATION?

ABSTRACT: The administration of Brazilian school systems is faced with two impasses: The speech on Democratic Administration in the formulation and implementation of Public Policies in Education and the "productivist" practice that "dispenses" with the first one. In

Pós-doutora em Educação e professora livre-docente da Faculdade de Educação da Universidade de São Paulo (USP). E-mail: liselaro@usp.br. 
Formulação e implementação das políticas públicas em educação...

addition to the social pressure movements for "transparency" in the government's actions, which demand extended popular participation - through Councils or equivalents -, the pressure for "quality" of education and "competent" educational management are requiring immediate answers from the Public Leaders. Since they have no conditions to give them, they establish public-private "partnerships" that implement the logics of the market in the orientations given to schools and in the public systems of education, creating a new and contradictory concept of educational efficiency, where the participation of the different segments of the school community is no longer needed.

Key words: Educational politics. Basic education. Public-private partnership.

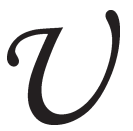
ma das questões polêmicas na área da educação e que se encontra presente na Constituição Federal (CF) de 1988 é o princípio educacional da gestão democrática. Contraditoriamente, é o único princípio constante da área educacional que teve sua abrangência limitada ao âmbito público, pois, nos termos do artigo 206, item vi, a gestão democrática ficou restrita ao "ensino público, na forma da lei".

Esta limitação, que poderia ser entendida como "distração", pelo caráter democratizante da Constituição, com claro incentivo à participação popular, representou, na verdade, um embate político em que o pensamento pedagógico conservador e privatista foi vitorioso. E esta circunscrição da gestão democrática escolar e educacional terá conseqüências mais extensas e permanentes do que se considerou inicialmente.

Mesmo estando garantidos os direitos de "ensinar e aprender", a partir do reconhecimento da necessária autonomia da prática docente e "do pluralismo de idéias e de concepções pedagógicas" (art. 206, itens II e III), estes direitos, na década seguinte à da promulgação da Constituição, começam a ser interpretados como o direito dos sistemas escolares estabelecerem currículos e programas minuciosos para orientar a prática pedagógica, à luz do proposto nos Parâmetros Curriculares Nacionais (PCNS).

De certa maneira, o Estatuto da Criança e do Adolescente (ECA - Lei n. 8.069/90) parece ter previsto esta possibilidade, pois, ainda em 1990, definiu como direito dos pais - direito este até hoje não respeitado ou implementado plenamente - a participação na definição das 
propostas pedagógicas das escolas de seus filhos, bem como ter conhecimento do processo pedagógico (art. 53, Parágrafo Único), acompanhando seu desenvolvimento e avaliação.

Também os alunos tiveram explicitado dois direitos que, à primeira vista, poderiam parecer dispensáveis, mas que a prática mostrou serem procedentes: primeiro, o direito de conhecer e contestar os critérios de avaliação da aprendizagem adotados por seus professores (art. 53, III - ECA); e, segundo, a obrigação do poder público estimular pesquisas, experiências e novas propostas educacionais, visando à inserção de crianças e adolescentes excluídos do ensino fundamental obrigatório (art. 57) e ao desenvolvimento pleno dos alunos que apresentem dificuldades de aprendizagem, fruto de suas condiçóes de vida e do contexto social e cultural em que vivem, garantindo-se sua liberdade de criação e de acesso às fontes de cultura (art. 58 - ECA).

A Lei de Diretrizes e Bases da Educação Nacional (LDB - Lei n. 9.394/96), ainda que num só artigo, propõe uma participação de caráter mais coletivo no processo de elaboração e decisão do projeto pedagógico de cada escola, prevendo a participação das comunidades escolar e local em "conselhos" escolares ou equivalentes (art. 14). Ou seja, estabelece que o "sucesso" do processo e do projeto pedagógico é fruto de uma reflexão mais coletiva do que tradicionalmente se admitia, e que sua adequação aos interesses e necessidades dos diferentes grupos de alunos definirá a qualidade de ensino. Pode-se deduzir, nesta concepção, que a "qualidade" só é evidenciada na implementação desta inter-relação de fatores.

Por outro lado, a definição das políticas educacionais dos diferentes sistemas de ensino - federal, estaduais e municipais - também tem como pressuposto uma ação mais solidária entre as esferas públicas, uma vez que o sistema federativo implica colaboração e distribuição, a mais eqüitativa possível, de responsabilidades e tarefas entre elas.

Esta é a razão por que a elaboração de planos de educação, atualmente, e pelo menos no discurso e na legislação, deixou de ser atividade exclusiva de "especialistas" que, historicamente, manipulavam dados estatísticos e informaçôes em seus gabinetes, para se tornar iniciativa democrática, em que os diferentes segmentos sociais são convidados a se pronunciar e a se envolver na definição de suas diretrizes e prioridades. 
Formulação e implementação das políticas públicas em educação...

As experiências históricas vêm mostrando (Pontual, 1995; Freire, 1991; Silva, 1998; Paro, 2005) que a condição de participação popular, em que os grupos sociais tiveram a possibilidade de conhecer de perto os dirigentes públicos e com eles discutir idéias, propostas e suas necessidades locais, regionais e nacionais, é que permitiu uma definição mais adequada de suas políticas e, em especial, uma maior coerência na sua implementação e na permanência dos investimentos financeiros.

As avaliações dos planos nacionais já elaborados no Brasil trienais, qüinqüenais ou decenais - explicitam que tais planos, a quase totalidade elaborada por especialistas ou tecnocratas sem contato com a realidade social, tiveram como objetivo maior o cumprimento de exigência burocrática, dispensando a participação dos grupos sociais que seriam atingidos por suas propostas, e, em função disso, acabaram se tornando "letra morta", pois ninguém se sentiu compelido ou comprometido em implementá-los.

São incontáveis os documentos oficiais, plenos de boas intenções, que não sensibilizam ou comprometem nem os gestores públicos, nem os grupos sociais, especialmente quando uma nova administração assume o governo. São, portanto, inúteis, ainda que cumpram um papel simbólico de atuação competente dos governos, como tradutores do suposto lema científico da excelência empresarial: "Competência é sinônimo de organização, planejamento e ação".

F. Whitaker Ferreira, em seu clássico livro Planejamento: sim e não, já no final dos anos de 1970, quando o conceito de planejamento foi introduzido de forma mais sistemática na gestão pública e generalizado seu uso nos diferentes setores, predizia a inutilidade de tal procedimento se os que sofressem a ação planejada não participassem da elaboração, acompanhamento e avaliação dos planos. Dizia ele (1981, p. 25): "Quem planeja mesmo é quem faz. O planejamento tem que ficar a serviço de quem está fazendo".

Um diagnóstico bem feito é não só aquele que levanta as diferentes variáveis e os dados da realidade, objetivamente, mas o que agrega, neste processo, a reflexão - e, em conseqüência, a formação - de diferentes grupos sociais. A identificação dos problemas e as diferentes alternativas para sua solução são processos que fortalecem uma perspectiva mais complexa da vida e da situação analisada. Os grupos sociais e 
populares envolvidos no processo de planejamento podem adquirir, por meio desse exercício coletivo, uma visão mais solidária do quanto o problema de um grupo afeta a solução ou o agravamento de outro. Isso lhes permitirá optar - e apostar! - em possibilidades, em que nem sempre a solução originalmente proposta é depois considerada viável ou oportuna.

Este é um processo que implica, por definição, uma tramitação democrática, em que o ritual de reuniōes sistemáticas preveja que todos os presentes possam se manifestar. Daí que as mesmas precisam ser realizadas com intervalos compatíveis, que permitam aos "representantes" dos diversos grupos - delegados eleitos ou escolhidos - consultar seus "representados", trazendo sempre reflexões e sugestões dos mais amplos segmentos.

A "pressa” nas decisões de políticas públicas compromete esse processo democrático - sempre mais lento - de consulta aos envolvidos. Não se trata de defender um "basismo" inercial, em que a consulta à população signifique um atrofiamento permanente de qualquer decisão rápida da gestão pública, mas de se admitir que a euforia pelos planejamentos de políticas públicas "baixados por decretos" é inócua, pois ineficaz, uma vez que em pouco tempo esses planos caem no esquecimento.

O Brasil, no entanto, possui boas e interessantes experiências de ampla participação popular na definição de políticas, nem sempre devidamente valorizadas. É oportuno lembrar duas recentes experiências, ousadas nos seus objetivos e abrangência participativa: a elaboração por educadores do Plano Decenal de Educação, "proposta da sociedade brasileira” - experiência histórica pioneira do final da década de 1990 - e a realização do Fórum Social Mundial, como reação e mobilização popular contra as políticas neoliberais, que vêm sendo implementadas em todo o mundo e que, apesar do discurso "inclusivo", espoliam cada vez mais os povos pobres e reduzem suas possibilidades de participar de processos de socialização dos bens mundialmente produzidos.

A experiência de elaboração coletiva de um Plano Decenal de Educação, envolvendo cerca de cinco mil educadores, a partir de encontros municipais, estaduais e nacionais, que iam selecionando e "refinando" os diagnósticos e as sugestões apresentadas para a universalização do atendimento da demanda e a melhoria da escola e dos 
Formulação e implementação das políticas públicas em educação...

sistemas públicos de ensino, em todos os níveis e modalidades, nunca havia sido experimentada. No entanto, ela foi realizada e o Congresso Nacional teve que considerar a proposta apresentada como referência, ao ser confrontada com a elaborada pelo governo federal, cujo projeto de Plano trazia, no máximo, o aval da ala institucional - a União Nacional dos Dirigentes Municipais de Educação (UNDime) e o Conselho Nacional dos Secretários Estaduais de Educação (CONSED), além do próprio Ministério de Educação (MEC). Estas entidades, por sua vez, não haviam realizado, democraticamente, reuniōes plenárias municipais e estaduais, com suas redes de ensino, para ouvir pais, alunos, professores, funcionários e outros grupos da comunidade escolar, sobre as propostas do governo. O resultado foi que, adotadas as metas e objetivos do governo, pelo Legislativo, o diagnóstico incorporado foi o do movimento social. Não por acaso, apesar do relator do Projeto de Lei na Câmara Federal ser um representante do partido do governo, o mesmo teve que realizar nove vetos no Projeto aprovado, todos eles com repercussão financeira nos sistemas públicos de ensino, anulando, na prática, o que de positivo havia sido proposto.

O Fórum Social Mundial constitui um outro bom exemplo, pois, contrariando todos os prognósticos, foi realizado diversas vezes na cidade de Porto Alegre (RS), a partir de 1998, reunindo, em cada evento, entre 60 mil e 150 mil pessoas, em torno de propostas que pudessem gestar alternativas - econômicas, políticas, sociais e culturais - ao atual modelo capitalista prevaricador. O Fórum, a partir da constatação de que este capitalismo "selvagem" vem engendrando um pensamento hegemônico, onde valores como a competição e o individualismo inumano entre países e pessoas vêm se estabelecendo, levando à falta de solidariedade grupal e internacional, em todos os setores, decidiu organizar movimentos e criar alternativas para que o capitalismo, como modelo econômico único, fosse enfrentado de maneira mais ordenada. Dessa forma, "o que" fazer, "quem" fazer, "quando" e "para que" fazer perguntas clássicas do bom planejamento - passam a ser fruto de propostas e resoluçóes de todos os participantes, gerando uma coresponsabilização coletiva pelo processo e pelo resultado das ações.

Como diferentes grupos sociais foram envolvidos nestes dois processos, em algum grau, as universidades públicas, como co-autoras do (novo) saber, também vêm colaborando na construção de alternativas, por meio de pesquisa e de extensão universitária, como possibilidades 
de reflexão e de formação política, traduzindo assim seu papel e sua responsabilidade na transformação social e cultural.

Contudo, estas realizações, expressão das possibilidades da participação popular numa concepção democrática, ainda que minoritárias no planejamento e implementação de políticas públicas, não podem ser vistas como simples exemplos de "utopias saudosistas", que marcaram a história dos povos, mas logo desapareceram, pois os "de baixo" deixam sempre suas marcas de forma breve e fugaz. Mas, ao contrário, constituem referências importantes para se entender que, na modernidade, a participação popular e a gestão democrática representam pontos frágeis e polêmicos também nos governos democráticos, constituindo-se espécie de resistentes "calcanhares de Aquiles" que impedem, contraditoriamente, o pleno desenvolvimento do (novo) discurso conservador.

Razões desse impasse na modernidade

Mas, afinal, quem vem definindo as políticas públicas em educação e que orientaçōes predominam nessas decisōes? Quem avalia se essas políticas são coerentes e pertinentes em relação a uma situação problemática diagnosticada, em especial, quando se trata de um país pobre, com problemas educacionais seculares?

O discurso da modernidade é explícito na valorização da qualidade, admitindo, num primeiro momento, diferentes critérios para sua definição e, num segundo, estabelecendo indicadores quantitativos que não necessariamente têm a ver com as decisões que, histórica e cientificamente, orientaram as intervenções nas políticas sociais. Por outro lado, a admissão de que os "usuários" também podem ser avaliadores das políticas implementadas, pois são eles que experimentam, no cotidiano, as práticas e as conseqüências dessas açōes, não tem se constituído na orientação predominante.

Ainda que algumas alternativas de acompanhamento e controle social pela população usuária não tenham sido bem sucedidas historicamente, das quais os Conselhos de Educação são bons exemplos, isto não pode significar o abandono ou a rejeição de qualquer nova tentativa, até porque uma disputa mais agressiva de sua autonomia e caráter independente vem se estabelecendo nos dias atuais. Recorde-se a infeliz trajetória dos Conselhos de Educação: criados nos anos de 1960, em função dos dispositivos da primeira LDB do Brasil - a Lei n. 4.024, 
Formulação e implementação das políticas públicas em educação...

de 11 de agosto de 1961 -, estes conselhos tinham por objetivo representar uma espécie de "quarto poder", onde a população, de forma organizada, pudesse estar representada, participando da proposição, acompanhamento e avaliação das políticas que o Executivo, por função, deveria implementar.

Aquele ato legal previa, pela primeira vez na história da educação brasileira, a voz dos usuários dos serviços educacionais: professores e pais, ao lado da de especialistas de educação, garantindo, no seu funcionamento, uma certa independência dos mesmos, do Poder Executivo, à semelhança dos "Boards of Education” norte-americanos - espécie de conselhos distritais, com grande influência nas escolas e pouca intervenção dos Executivos locais. Estávamos, no Brasil, conhecendo e experimentando projetos pedagógicos e educacionais trazidos pelo movimento da "Escola Nova", que propunha, com novas metodologias de ensino, mais ativas, o incentivo à criação de grêmios estudantis e de associação de pais, onde alunos e pais pudessem discutir os projetos pedagógicos das escolas. Eram tempos do "nacional-desenvolvimentismo", quando a criação do "homem novo" dependia - quase numa relação direta - da educação, e daí a necessidade de se construir a sua contemporaneidade, na democratização das oportunidades educacionais que, por sua vez, implicava maior participação de todos no projeto pedagógico, para que se viabilizasse uma radical reformulação da escola pública.

O fato é que, no bojo do movimento da "Escola Nova", estes novos personagens são convidados a participar de forma mais ativa da vida das escolas e integrar esses conselhos, na época, propostos, exclusivamente, em níveis estadual e nacional. Em princípio, a composição destes conselhos deveria privilegiar a combinação: especialistas em educação e representantes das diferentes modalidades e níveis de ensino "de notório saber e conduta ilibada" - e população usuária, com relativa autonomia em relação à estrutura institucional vigente - daí a idéia de "quarto poder".

Nasciam, assim, os conselhos federal e estaduais de Educação. $\mathrm{Na}$ prática, porém, essa concepção de conselhos não floresceu, pois, implantados em 1963, foram descaracterizados pelo Golpe Militar de 1964, já em 1965, uma vez que a representação e os critérios de escolha democrática de seus membros foram restringidos. Os tempos e os 
conceitos de participação e liberdade de pensamento haviam mudado, matando, na origem, uma concepção democrática de elaboração de políticas e projetos educacionais, com relativa independência do Executivo.

Por coerência com o novo momento histórico, uma visão tecnocrática da educação é estabelecida, onde o controle das ações educacionais é sempre do Poder Executivo, e a descentralização das ações, uma simples estratégia organizacional, que visa somente uma maior racionalidade dos recursos utilizados e o desenvolvimento mais rápido e menos oneroso dos fins previstos para a escola e a educação, reafirmando os termos da reforma administrativa da época (Decreto-Lei n. 200/1967), cuja diretriz principal era a "descentralização das ações e centralização das decisões".

Uma nova "terminologia" é introduzida no vocabulário educacional, que gera - por exigência da "nova ordem” política - a prática de planejamentos detalhados e detalhistas, onde os conceitos de competência, produtividade, eficácia e eficiência das ações passam a estar presentes no cotidiano escolar. Evidentemente, não se tratava de mera modificação lingüística, com a introdução de termos "vazios", mas de uma nova concepção da ação educativa e do uso de novas metodologias agora chamadas de "estratégias pedagógicas e táticas do trabalho docente" - para se realizar o trabalho nas escolas com maior competência, avaliando os objetivos educacionais com maior objetividade.

Fundamentada na utilização dos conceitos e da terminologia da teoria dos sistemas, nascia uma proposta - que perdura - de individualização na cobrança de resultados educacionais, pois, a um "input”, objetivamente definido e escolhido, corresponderia um "output" previsto e desenvolvido, por meio dos quais se poderia realizar uma competente "avaliação de desempenho" de professore e alunos. Os novos estudos da psicologia comportamentalista contribuíram, involuntariamente, para esta distorção, fundamentando a nova proposta.

São dessa época os Planos de Implantação da Reforma de $1^{\circ}$ e $2^{\circ}$ Graus - conseqüência da $2^{\mathrm{a}} \mathrm{LDB}$, a Lei n. 5.692, de 11 de agosto de 1971, conhecida como a "lei dos militares" - e os "Guias Curriculares", protótipo de currículo único, onde os professores deveriam buscar a fundamentação e as sugestões para as suas ações pedagógicas.

No entanto, há que se admitir historicamente que, passados a euforia pelo combate e resistência à ditadura militar, de mais de vinte 
Formulação e implementação das políticas públicas em educação...

anos de duração, e o movimento constituinte por uma nova organização legal e política do país, foi no final dos anos de 1990 que a proposta tecnocrática, já experimentada nos anos de 1970, voltou com força surpreendente à cena política e educacional.

Assim, vivemos hoje, na educação e em outros setores sociais, uma aparente contradição inesperada: superados a ditadura militar e o sistema autoritário de governo, os que o sucederam vêm mostrando o quanto suas marcas são persistentes e, algumas, indeléveis. Não se apaga o passado "com uma borracha", nem se superam comportamentos autoritários que foram sendo estabelecidos ao longo dos anos na ponta de lanças - pelo combate a idéias, valores e crenças. Esquecemo-nos da influência desse passado próximo no cotidiano atual e nos surpreendemos, por isso mesmo, cada vez que um dirigente político ou gestor público do país nos lembra sua "autoridade", utilizando-se de medidas de intimidação e constrangimento; em particular, e cada vez mais freqüentes, menosprezando as manifestações e opinióes dos setores organizados do país, quando estas defendem idéias contrárias às do governante de plantão. Aí, muitas vezes, a simples divergência é insuportável e as respostas, semelhantes às dos sistemas autoritários de então.

Esta concepção gera, como prática, uma "competência amorfa", em que a aparente neutralidade científica e pedagógica, que deveria fundamentar os planejamentos escolares, acaba sendo usada como argumento para "cobrar" das escolas e dos professores das redes públicas de ensino a escolha de conteúdos similares, em nome do dever da oferta como direito de todos os cidadãos brasileiros -, de uma formação "básica e comum" a todos os alunos.

Esta "preocupação" oficial já havia fundamentado a proposição de Parâmetros Curriculares Nacionais (PCN), documento de quase mil páginas elaborado e divulgado pelo governo federal, a partir de 1997, de forma extensiva às redes de ensino. Estes "parâmetros", que no início de sua divulgação eram apresentados como "sugestões", vêm sendo adotados, independente das condições objetivas de vida e de trabalho dos professores e dos alunos, e de funcionamento das escolas, pois são eles que orientam as opções e os conteúdos das questôes de múltipla escolha dos exames e provas nacionais, agora como principal critério de avaliação da "qualidade de ensino" e do "desempenho escolar" para todos. 
Estavam criadas, na avaliação do governo, as condições históricas e pedagógicas para a introdução das provas únicas, elaboradas e aplicadas em todo o país. Este caminho ganhou, com a aprovação da Emenda Constitucional n. 14/1996, o seu fortalecimento, pois, com a criação do Fundo de Manutenção e Desenvolvimento do Ensino Fundamental e Valorização do Magistério (FUNDEF), remunerou-se, pela primeira vez na história da educação brasileira, o serviço público educacional, pelo número de atendimentos que as esferas públicas estaduais e municipais realizavam. Este novo sistema acabou incentivando um processo sumário de municipalização do ensino fundamental, em especial o das suas séries iniciais e, particularmente, em percentual acentuadamente maior, na região nordeste, a mais pobre do Brasil. Assim, considerando-se exclusivamente as redes públicas estaduais e municipais do país, passamos de um atendimento municipal do ensino fundamental, em 1996, de 54,4\% e de um estadual de 45,6\% para, em 2006, os surpreendentes índices de $62,8 \%$ e $37,15 \%$, respectivamente. Estes dados são mais incríveis ainda, quando se observa a situação da região nordeste, pois, de 45,6\% de atendimento estadual no ensino fundamental e $54,4 \%$, nas redes municipais, em 1996, atingiu-se $23,3 \%$ e $76,7 \%$ de atendimento, respectivamente, em 2006. Ou seja, atualmente, três quartos dos alunos de todo o ensino fundamental do Nordeste são atendidos pelas prefeituras municipais, grande parcela delas, em precárias condiçóes de funcionamento.

Apesar de o discurso oficial priorizar, como objetivo do FUNDEF, a universalização do ensino fundamental, na prática só os alunos de 7 a 14 anos de idade tiveram suas matrículas garantidas, uma vez que a educação de jovens e adultos foi inconstitucionalmente excluída da possibilidade de utilização dos recursos do FUNDEF. Mesmo assim, os prefeitos municipais, em especial os das cidades mais pobres, aderiram ao Fundo, municipalizando em número significativo suas redes, às vezes, até todo o ensino fundamental, com a motivação convincente de que novos e significativos recursos financeiros chegariam aos seus municípios.

Algumas prefeituras municipais concordaram, inclusive, com a simples transferência de alunos das redes estaduais para as municipais, uma vez que, nesta faixa etária, o atendimento nacional já havia atingido $93 \%$ da população. Os dados dos censos educacionais (INEP/MEC) mostram que o total de atendimentos de alunos do ensino fundamental, 
Formulação e implementação das políticas públicas em educação...

em 1996, era de 33.131.270, e em 2006, 33.282.663, ou seja, o crescimento foi de pífios 150 mil alunos. No entanto, em 1996, as redes estaduais eram responsáveis por cerca de 18 milhões de alunos e as redes municipais por 11 milhões; em 2206, constata-se praticamente uma inversão da esfera pública responsável por esses atendimentos: as redes estaduais passam a ter cerca de 12 milhóes de alunos e as municipais, 18 milhões. Em conseqüência desta política educacional, podese afirmar que - com exceção das regiões sul, centro-oeste e parte da sudeste - o ensino fundamental é responsabilidade quase total dos municípios, em especial os localizados nas regiões mais pobres do país, com precárias condiçóes de funcionamento seja em termos de pessoal, instalações, condições de trabalho ou qualidade de ensino.

Como esse processo foi implementado de forma abrupta, evidentemente os municípios não tiveram tempo, nem condiçôes técnicas e financeiras, de se prepararem para esse aumento de responsabilidades. As consequiências não se fizeram esperar: realizados os exames nacionais, o desempenho foi insatisfatório na quase totalidade desses municípios, tanto nas provas do Sistema Nacional de Avaliação do Ensino Básico (SAEB), criado no início dos anos de 1990 e promovido através da mídia, nos dois governos de Fernando Henrique Cardoso (1995/98 e 1998/2002), como um dos instrumentos mais competentes de avaliação do desempenho escolar, quanto na Prova Brasil - criada no final do primeiro governo Lula (2003/ 2006).

Embora não se possa afirmar que um processo de privatização strito sensu esteja em curso, é evidente que a precariedade de recursos, combinada com as políticas de focalização adotadas no ensino fundamental, tende a induzir os municípios, frente às dificuldades de atendimento da demanda e da oferta de um padrão de qualidade mínimo, a buscar alternativas - e apoio - no setor privado.

Observe-se que, desde 1995, a cada biênio, realizam-se exames nacionais no Brasil, para "medir" o desempenho escolar de alguma etapa, nível ou modalidade de ensino. Atualmente, são seis os "exames" nacionais. Para avaliar o ensino fundamental, são utilizados os seguintes instrumentos: o SAEB, a Prova Brasil e a recém-criada "Provinha" Brasil, para os alunos dos primeiros anos do Ciclo I do ensino fundamental, agora que ele se inicia a partir dos 6 anos de idade. Para o ensino médio, tem-se o Exame Nacional do Ensino Médio (ENEM); para 
o ensino superior, o Exame Nacional de Desempenho de Estudantes (ENADE), que compõe o Sistema Nacional de Avaliação do Ensino Superior (SINAES); e, para a educação de jovens e adultos, o Exame Nacional para Certificação de Competências de Jovens e Adultos (ENCCEJA).

A divulgação dos resultados desses exames - todos eles - por meio da mídia escrita e falada, a cada dia se torna mais freqüente, levando a um processo de "ranqueamento" bastante acentuado, mesmo que oficialmente os governos digam que este não é o objetivo principal - nem mesmo o desejável - daquelas provas ou exames.

Contudo, é evidente que esse objetivo, ainda que "oculto", desempenha um papel fundamental na consolidação dessa forma de avaliação, pois a competitividade é apresentada como uma sadia variável que estimula e "emula" as crianças e os jovens a se dedicarem às atividades escolares. Sair-se bem nas provas nacionais deve ser, portanto, o desejo e o objetivo de todos. Como tal, pais, professores e dirigentes escolares devem considerá-las como um saudável sistema de avaliação externa, objetivo e adequado às "diferentes realidades nacionais”, e adotar os seus conteúdos como referencial indispensável nas propostas pedagógicas.

Para bom observador, vai ficando evidente que, em pouco tempo, pelo efeito repetitivo e de exposição na mídia, não será mais o governo que imporá - como hoje o faz - a obrigatoriedade desses exames, mas a população passará a exigi-los, como critério "transparente e universal" de conhecer e comparar as avaliações educacionais e o desempenho de "seu" filho, da professora de "seu" filho, da "sua" escola e, em seguida, das escolas do bairro, da cidade e do país - e, quiçá, do mundo.

Essa pode ser considerada uma das formas modernas de competente convencimento da adequação de novas políticas educacionais, especialmente quando as mesmas contrariam convicçóes pedagógicas, defendidas por parte significativa dos educadores, durante muitos anos. No caso, a de que a avaliação é processual, diversificada, devendo ser realizada durante todo o ano letivo, priorizando os aspectos qualitativos sobre os quantitativos, conforme a própria LDB estabelece.

Quais as conseqüências próximas que estas novas "crenças" trazem?

Em primeiro lugar, a perda de referência em relação à própria definição dos objetivos da escola, ou de sua "missão", confundindo-se 
Formulação e implementação das políticas públicas em educação...

seu objetivo permanente de socialização dos conhecimentos, realizado a partir de uma seleção crítica e variável de conteúdos, considerados os diferentes grupos-classe, que lhes possibilite uma sólida formação intelectual, com um caráter efêmero e quase místico da função da escola uma escola sem diferenças e desigualdades sociais, em que as novas tecnologias (a internet, em especial) superam as origens de classe.

Para efetivar este objetivo, torna-se fundamental uma formação crítica e autônoma do professor, capaz de escolher, entre concepções, metodologias e fundamentações pedagógicas, os melhores aspectos a ser trabalhados com cada grupo de alunos. No processo "moderno" de aligeiramento da formação profissional, do qual a formação docente não escapou, esta condição de trabalho vai-se esmaecendo, ficando presente, cada vez mais, só a valorização de uma determinada seleção de conteúdos que garanta a aprovação ou "o sucesso" de seus alunos nos exames nacionais realizados, colocando o aluno e a escola no patamar dos "vencedores". Afinal, no mundo moderno, o sucesso é dos (poucos) "vencedores", já que atender a "todos" com qualidade vem se tornando um objetivo longínquo e oneroso que nenhuma política social de Estado poderia suportar. Reconceituar, portanto, a noção de "direito de todos", reformulando-o para "direito por eqüidade", será a conseqüência mais próxima.

Como reforço "emulativo" aos professores, são adotadas remunerações salariais que acompanham pari passu o desempenho de cada professor dentro da lógica "produtivista" de resultados. Sua remuneração mensal será proporcional ao número de alunos que se saírem bem nas provas e exames, elaborados por especialistas internos à escola ou externos a ela. Ou seja, sistematicamente, seu salário poderá estar variando de valor, em função do melhor ou pior desempenho do grupo-classe ou do grupo-escola.

Este novo modelo de avaliação da "missão" educacional introduz no cotidiano escolar não mais a perspectiva democrática do direito de todos a uma educação de qualidade, mas a necessidade de se admitir, pedagógica e culturalmente, que a metodologia adequada - e única, já que a prática bem sucedida mostrou sua adequação - é a que propicia e estimula "o melhor de cada" aluno - que é seu desejo de vencer -, quaisquer que sejam seus "adversários" mais próximos, antes chamados de colegas e amigos. 
A dúvida que poderia inquietar os gestores educacionais seria saber como cada um dos alunos e seus esforçados professores - nem sempre portadores de uma sólida formação inicial - conseguiriam este feito. Como garantir que cada escola, e todas elas - porque isso é democrático! - atinjam um alto score nas provas e sejam consideradas "vencedoras"? Contando, certamente, com a colaboração de quem "sabe" fazer isso, de quem vem fazendo desse jeito e tem tido sucesso: as escolas privadas, seus centros ou institutos de assessoria e as organizaçóes não-governamentais que as representam. E este "modo de fazer", de conseguir ser sempre competente e de premiar os vencedores, já está entre nós e, em particular, nos sistemas públicos de ensino.

$\mathrm{O}$ ato legal precursor de tal concepção, veiculado em meados de 1995, sob a liderança do ministro da Modernização Administrativa e Reforma do Estado (MARE), Luiz Carlos Bresser Pereira, no primeiro Governo Fernando Henrique Cardoso, é a Emenda Constitucional n. 19, de 4 de junho de 1998, que "modifica o regime e dispõe sobre princípios e normas da Administração Pública (...)”, reformando o Estado brasileiro e introduzindo dois novos princípios - o de que o "interesse público" não necessariamente é estatal, com a conseqüente inclusão do conceito de "público não-estatal", pela primeira vez na Constituição Federal; e o segundo princípio, o de que os serviços até então considerados privativos do Estado poderão ser, mediante contratos, transferidos ou "gerenciados" pela iniciativa privada.

Não se trata aqui da promoção de qualquer movimento progressista de auto-gestão e de combate ao poder alienante do Estado. Ao contrário, o Estado usa seu poder de "mando" para legitimar o processo de mercantilização e de privatização do ensino e da educação. A fase do quase-mercado está sendo superada. Estamos na fase seguinte, de privatização sumária, em nome da eficiência, com redução significativa dos investimentos nas políticas sociais.

Contudo, caso o "novo" administrador desejar - ou precisar ampliar a autonomia gerencial, orçamentária e financeira dos órgãos e entidades da administração pública que lhe foram "transferidos", basta que se estabeleçam "metas de desempenho", conforme disposto no $\$$ $8^{\circ}$, do artigo $3^{\circ}$, da EC 19/98. Ou seja, em nome da "eficiência" da ação pública e da eficácia dos investimentos, os administradores privados podem estabelecer modificações não só gerenciais, mas orçamentárias e de processo, em qualquer órgão que lhes for "contratado". 
Formulação e implementação das políticas públicas em educação...

Trata-se de inacreditável "voto e acordo de confiança" entre o poder público e o novo "administrador", que a lei até faculta ser outro órgão da administração pública - alternativa esta minoritária -, mas que tem fundamentado o repasse sumário de atividades, serviços e órgãos públicos - como os hospitais, por exemplo - à iniciativa privada.

É importante destacar que não se está discutindo, neste caso, a conveniência pública e política de determinados serviços serem co-realizados por meio de parcerias público-privadas, onde o poder público admite sua incompetência relativa e transitória de não cuidar ou atender, de forma imediata, alguns setores historicamente desprestigiados. $\mathrm{Na}$ área educacional, são consideradas "extensões" do Estado - pela ausência dele - as creches da periferia, cujas mães trabalham o dia todo, ou a educação de jovens e adultos, oferecida em locais verdadeiramente próximos das residências dos alunos, cuja precariedade e pobreza obrigam ao funcionamento precário - mas, indispensáveis - de sistemas semi-oficiais de educação, em especial nas baixas exigências para suas instalações.

Em 2005, o então prefeito municipal da cidade de São Paulo José Serra -, com menos de seis meses de Gestão, propôs, por meio de Projeto de Lei (PL), a transferência da gestão de equipamentos públicos nas áreas da saúde e da educação para organizaçóes sociais privadas, em especial para Organizaçóes da Sociedade Civil de Interesse Privado (OSCIP), criadas pela Lei n. 9.790, de 23 de março de 1999. Em relação à proposta de privatização da gestão de hospitais municipais, a mesma foi aprovada. A de privatização da gestão de creches municipais foi provisoriamente excluída do PL, por negociação com os Sindicatos de Profissionais de Educação, em função de greve do magistério municipal, que acontecia naquele momento. Neste PL, ficava autorizado aos novos administradores poder estabelecer nova hierarquia salarial, diferente da estabelecida no Estatuto do Magistério ou no Plano de Cargos e Salários dos Servidores Municipais. Tudo em nome do melhor e mais rápido cumprimento das "metas de desempenho" estabelecidas.

Atente-se que, há dez anos, o então prefeito municipal da mesma cidade de São Paulo - Paulo Salim Maluf - tentou aprovar projeto de lei assemelhado, conseguindo fazê-lo somente para a área da saúde, quando foi criado o Programa de Assistência à Saúde (PAS), e cujos escândalos de desvios de recursos e de superfaturamento nos equipamentos e materiais hospitalares, depois de três anos, ficaram de conhecimento público. 
Naquela ocasião, a área da educação reagiu de forma tão negativa, com protestos sistemáticos de diferentes setores, que o governo considerou desgaste político desnecessário a insistência na sua aprovação, mesmo tendo dificultado, com exigências maiores, em novo PL, as condições para que esse processo de privatização de gestão fosse colocado em prática. Não se pode afirmar, no entanto, dez anos depois, que as reaçóes da sociedade e dos educadores paulistanos tenham sido tão dramaticamente violentas quanto às anteriores. Ao contrário, grupos anteriormente dissidentes da proposta mantiveram-se em total silêncio nesse novo momento histórico da gestão pública.

Este novo conceito de competência de gestão pública que estava se instalando teve repercussões que afetam a gestão educacional dos municípios? No processo turbulento e até irresponsável de municipalização de todo ou de parte significativa do ensino fundamental, seus dirigentes educacionais não conseguiram organizar, com um mínimo de condições objetivas e dignas de trabalho, um cotidiano escolar que favorecesse o florescimento de experiências pedagógicas singulares e interessantes nas suas redes públicas de ensino. Nem mais acreditam que seus professores sejam capazes de propor projetos de excelência pedagógica para suas escolas e, assim, para que não sejam novamente apontados como exemplo de um "pobre ensino pobre", vêm adotando "contratos" com metas de melhoria de desempenho, em curto e médio prazos, com escolas e instituições que pouco ou nada têm a ver com suas cidades, suas histórias e seus moradores.

O jornal Folha de S. Paulo publicou matéria em 2006 (Caderno "Cotidiano", 30 jan. 2006, p. 3), onde informava que 145 cidades no Brasil, das quais 129 se localizavam no estado de São Paulo, haviam firmado convênios ou contratos com sistemas privados de ensino, considerados "bem sucedidos" ou "de sucesso" - dentre outros exemplos citados, o Colégio Oswaldo Cruz (COC), o Objetivo e o Anglo - para a "socialização" de seus métodos de ensino com as redes públicas de ensino. São escolas que atendem crianças privilegiadas, do ponto de vista socioeconômico, para "emprestarem" seus métodos de trabalho para ser "copiados" ou adotados pelas escolas da rede pública. Estes "pacotes" têm sido vendidos em todas estas cidades e, conforme as referidas empresas educacionais, prevêem expansão para todo o país. Os "kits pedagógicos" são compostos por um conjunto de apostilas e cadernos de orientações para o professor e para o aluno, com treinamento para os 
Formulação e implementação das políticas públicas em educação...

professores e planejamentos pedagógicos previamente elaborados, sem nenhuma consideração às diferenças de "clientela" a que se dirigem. No início de 2007, o mesmo jornal (Caderno "Cotidiano", 17 abr. 2007, p. 5) afirmava que essa modalidade de "assessoria" já atingia mais de 200 municípios e suas escolas, só no estado de São Paulo, que buscavam, assim, conseguir a fórmula do "sucesso" que, por si só, não tinham sido capazes de criar.

É evidente que, tempos depois, com o uso permanente de material pedagógico idêntico, com conteúdos semelhantes, sem nenhuma adaptação aos diferentes grupos de alunos e com atividades e exercícios "padrão sucesso" já testados, os professores acabam se "acomodando" na situação, pois se, de um lado, sabem que esse sistema não levará a qualquer processo emancipador de nenhum dos grupos sociais com que trabalha, por outro, ele se poupa, pois não precisará ouvir, com freqüência ensurdecedora, sobre sua incompetência profissional e sua incapacidade de obter resultados significativamente melhores, em curto prazo, com todos os alunos, sem alteração de suas condiçóes de trabalho.

De agora em diante, adotado este processo de "transferência do saber" - igual para todos, independente de suas condições de vida e desigualdades sociais -, se o aluno não conseguir êxito escolar, o problema e a responsabilidade poderão ser transferidos a ele e sua família: "culpa" do aluno, porque não se dedica o suficiente às atividades e deveres escolares, e da família, porque não o estimula ou o acompanha na freqüência e ritmo necessários.

Adotando estas políticas na área educacional, onde a percepção da baixa qualidade da educação pública oferecida justifica a tese de que a adoção destas "estratégias" - ainda que aparentemente provisórias colaborariam (pois elas são "parceiras") para tornar mais eficientes o trabalho educativo e os projetos das escolas, certamente a gestão democrática, com participação popular sempre crescente e suas intermináveis discussões, reunióes, sugestóes e cobranças, é empecilho a ser superado, por desnecessário.

As conseqüências da implementação dessa política são previsíveis: cada vez mais, o Estado buscará "parceiros" para dividir sua responsabilidade educacional, tanto com relação ao atendimento da demanda e da oferta, em especial, por meio do estabelecimento de contratos com 
creches comunitárias, ou convênios para o atendimento em educação especial, ou mesmo para o funcionamento de classes de educação de jovens e adultos em associações filantrópicas ou comunitárias, quanto com relação à qualidade, com contratos e convênios com escolas e sistemas privados de ensino para "transferência" sumária de métodos e técnicas de ensino e de compra de materiais "unificados" e adequados para o "sucesso" nas provas ou exames nacionais - reservando-se ao Estado a função exclusiva de definir o "produto esperado" (educação para a cidadania?) e os mecanismos de aferição da qualidade do "produto efetivamente produzido" (aluno "civilizado" e cidadão?).

Esta é a nossa verdadeira questão: Se as políticas educacionais caminham nessa direção, para onde aponta o "futuro"? Abriremos mão, em definitivo, por inexeqüível na democracia, de um projeto de participação popular e de emancipação dos nossos alunos e dos diferentes grupos sociais que estão presentes nas escolas?

Hobsbawm e Freire têm possíveis respostas. Diz o primeiro (1995, p. 562): "O futuro não pode ser uma continuação do passado, e há sinais, tanto externamente quanto internamente, de que chegamos a um ponto de crise histórica. (...). Nosso mundo corre o risco de explosão e implosão. Tem que mudar”. Freire (1991, p. 43) completa: "A mudança do mundo implica a dialetização entre a denúncia da situação desumanizante e o anúncio de sua superação: no fundo, o nosso sonho".

Se acreditarmos nisso, só nos resta um dever: remar contra a corrente do capitalismo desumano considerado inexorável e propor, resistindo com novas práticas, que política pública e educacional, para ser "competente", tem que ter cheiro, voz e ação das "gentes". Tem que ter ruptura. Tem que ter povo. Humanizado. Informado. E com o sonho de um dia ser feliz, numa sociedade menos injusta e, aí sim, socialmente competente.

Recebido em julho de 2007 e aprovado em agosto de 2007.

\section{Referências bibliográficas}

BRASIL. Constituição (1988). Constituição da República Federativa do Brasil, promulgada em 5 de outubro de 1988. São Paulo: ImEsP, 2002. 
Formulação e implementação das políticas públicas em educação...

BRASIL. Emenda Constitucional n. 14, de 12 de setembro de 1996. Modifica os art. 34, 208, 211 e 212 da Constituição Federal e dá nova redação ao art. 60 do Ato das Disposições Constitucionais Transitórias. Diário Oficial da Uniāo, Brasília, DF, 13 set. 1996.

BRASIL. Emenda Constitucional n.19, de 4 de junho de 1998. Modifica o regime e dispõe sobre princípios e normas da Administração Pública, servidores e agentes políticos, controle de despesas e finanças públicas e custeio de atividades a cargo do Distrito Federal, e dá outras providências. Diário Oficial da União, Brasília, DF, 5 jun. 1998.

BRASIL. Lei n. 5.692, de 11 de agosto de 1971. Estabelece as Diretrizes e Bases da Educação Nacional. Brasília, DF: MEC, 1972.

BRASIL. Lei n. 8.069, de 13 de julho de 1990. Dispõe sobre o Estatuto da Criança e do Adolescente. Diário Oficial da União, Brasília, DF, 16 jul. 1990. Disponível em: <http://www.mec.gov.br/secad.> Acesso em: 20 ago. 2004.

BRASIL. Lei n. 9.394, de 20 de dezembro 1996. Estabelece as Diretrizes e Bases da Educação Nacional. Diário Oficial da União, Brasília, DF, 23 dez. 1996. p. 27894. Disponível em: <http:// www.mec.gov.br/legislacao> Acesso em: 23 mar. 2005.

BRASIL. Ministério da Educação. Instituto Nacional de Estudos e Pesquisas Educacionais (INEP). Sinopses estatisticas, 1996 e 2006. Disponível em <http://www.mec.gov.br/inep/estatisticas>. Acesso em: 15 jul. 2007

COSTA, V.L.C. (Org.). Descentralização da educação: novas formas de coordenação e financiamento. São Paulo: Cortez; fUndAP, 1999.

FERREIRA, F.W. Planejamento: sim e não. 2. ed. Rio de Janeiro: Paz \& Terra, 1981.

FREIRE, P. A educação na cidade. São Paulo: Cortez, 1991.

FOlHA de S. Paulo, São Paulo, 30 jan. 2006. Caderno Cotidiano, p. 3.

FOLHA de S. Paulo, São Paulo, 17 abr. 2007. Caderno Cotidiano, p. 5. 
HARVEY, D. Condição pós-moderna. 4. ed. São Paulo: Loyola, 1989. HOBSBAWM, E. A era dos extremos: o breve século xx (1914 -1991). São Paulo: Cia das Letras, 1995.

PARO, V.H. Administração escolar: introdução crítica. 13. ed. São Paulo: Cortez, 2005.

PONTUAL, P. Construindo uma pedagogia democrática de poder. Polis, São Paulo, n. 15, p. 25-35, 1995.

SILVA, L.H. (Org.). A escola cidadã no contexto da globalização. Petrópolis: Vozes, 1998. 